\title{
Espírito da Diplomacia
}

\author{
Ministro Altamir DE MOURA \\ (Chefe da Divisão de Fronteiras do M.R.E.)
}

Itamaraty, com a sua habitual elegância, recolheu, há pouco, em brilhante e expressiva cerimônia, mais alguns jovens recém-diplomados pelo Instituto Rio Branco. Novas esperanças e novas promessas. Começa, assim, a carreira para os bisonhos diplomatas. Dois anos de estágio na Secretaria de Estado e, depois, a viagem de longo curso, onde as miragens douradas são mais freqüentes do que as realidades rosadas.

Mas, é viajando sem lamúria, é observando sem escândalo, é renunciando sem alarde, que se compreende a carreira diplomática. Quem se enamora de um quadro, mesmo colorido de uma visão modesta, sente o artista. $\mathrm{E}$ os diplomatas são como êsses magos do pincel que sabem transformar o areal numa paisagem pitoresca.

Nada de técnicos. Basta integrar-se no espírito da carreira. A diplomacia tem a sua cultura peculiar. $\mathrm{Na}$ arte diplomática sempre somos aprendizes. Nada pior para o diplomata do que alardear sua cultura e inteligência. Uma e outra, sabe-se, definem-se na equação do tempo.

O diplomata não é um ser privilegiado, mas, apenas, um espírito de élite. A vulgaridade não se instala na diplomacia. Por isso mesmo o Itamaraty, através de seu Instituto Rio Branco, cuida de preservar a carreira de elementos incompatíveis com a sua tradição.

Há, nos dias que correm, uma tendência de técnizar o homem. $\mathrm{Na}$ diplomacia, porém, há normas mas não técnica. Diplomacia "nova" e "velha" diplomacia são palavras proferidas a gôsto de cada um. Na sua essência, a diplomacia é uma só, porque a natureza humana é sempre a mesma no linguajar diplomático.

O diplomata é elemento que se não improvisa. Relanceando as páginas diplomáticas, sente-se o desprêso dos mestres pelos falsos diplomatas. Já se disse que a função da diplomacia não consiste em inventar fórmulas abstratas, nem nortear a ação política em planos artificiais. Consiste, isso sim, em interpretar as leis naturais, em humanizar os instintos e, principalmente, em ajustar os interêsses por meio de fórmulas conciliatórias.

Sainte-Beuve observava que o simples julgamento dos homens através do concurso é apenas uma das aparências da justiça. Ao lado da cultura, há o saber viver, há a penetração do espírito, há, enfim, o essencial - o diplomata. E o Embaixador WLADEMIR D'ORMESSON, em Enfance Diplomatique, escreve com muito acêrto: Un homme tout d'une pièce n'est jamais um bon 
diplomate. Il n'y a pas de méthode diplomatique qui soi valable dans tous lest cas. Les affaires extérieures se manient comme un cheval difficile, tantôt en rendant les rênes, tantôt en les rassemblant.

Em épocas mais recuadas, prevalecia o dom da oratória como a mais essencial das qualidades para o exercício de funções diplomáticas. ToRQuato TAsso, no "Diálogo" sôbre os embaixadores, era de opinião que ninguém poderia ser perfeito embaixador sem a vocação oratória. E o próprio Octaviani Maggi, célebre jurista veneziano, considerava atributo primordial do embaixador a eloqüência suprema, que é, no seu entender, o dom mais precioso concedido por Deus ao gênero humano.

Outra, no entanto, seria a concepção de um diplomata no decurso do século XIX: bons costumes, julgamento sólido, espírito suave e flexível, coração nobre e elevado. Há, desde então, como se vê, uma tendência de "criar" diplomatas, cujo conhecimento do métier é a maior garantia de um Govêrno.

TALlEYRAND, pouco antes de morrer, inspirou-se no seu discurso de elogio ao conde de Reinhard, pronunciado na Academia de Ciências Morais e Políticas: Je dois le rappeler ici, pour détruite un préjugé assez généralment tépandu - la diplomatie n'est point une science de ruse et de duplicité. On a voulu confondre la réserve avec la ruse. La bonne foi n'autorise jamais la ruse, mais elle admet la réserve. Et la réserve a cela de particulier: c'est qu'elle ajoute à la confiance.

Nos seus "Conselhos aos jovens diplomatas", HofFMANN vem em socorro dos velhos mas sempre novos principios diplomáticos. E com êles estão igualmente Maurice Bompard, Jules Cambon, J. Jusserand.

Em diplomacia é preciso saber agradar. Agradar, bem entendido, sem dissimulação. A arte de não ser enganado, mas de inspirar confiança a todos, repousa sôbre a palavra empenhada. LACORDAIRE, numa de suas "Cartas aos jovens", escreveu: Autre chose est de mentir à sa pensée, autre de se taire.

Ao tempo em que a trapaça, o ardil e a perfídia adquiriram foros de modelagem diplomática, já o Duque de Choiseul fazia sentir que a verdadeira nobreza era a verdade. As maneiras de um felino não são dignas de um diplomata. A cortesia exagerada pode refletir um homem astuicioso, jamais um diplomata.

Tudo em diplomacia é simples. Nada de sentenças gravés, nem de alocuções proféticas. Meditar sôbre o passado, para melhor conhecer o presente, não é cingir-se à rotina, mas, e principalmente, preservar a diplomacia do espírito de aventura. A diplomacia deve se manter em equilíbrio no limite da prudência. Je veille pour raccommoder, disse Vergennes, e, até hoje, assirn, o fazem os perfeitos diplomatas.

Evidentementé, cada século possui o segredo de suas fórmulas de cortesia. Mas, o noveau-venu contrasta sempre com a tradição. Montebelo, que foi Embaixador em São Petersburgo, conta o seguinte fato, quando de sua colaboração no Gabinete do Conde de Moustier, Ministro dos Negócios Estrangeiros de Napoleão III: "Escreva, por favor - disse-lhe o Ministro nesta minha carta de resposta o pior dos fechos de cortesia". E Montebelo, não ignorando que tal impropriedade poderia provocar todo um duelo epistolar, consultou o formulário em uso e, com a consciência tranquila, anotou

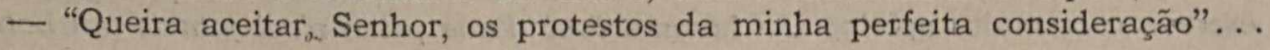


As nuanças, tão frequentes na diplomacia, dissipam-se com a bonomia, que é uma das qualidades de quem vive em meio a um simples mas delicado jôgo de idéias. $O$ excesso de otimismo ou pessimismo, de loquacidade ou pedantaria, de presunção ou estouvamento, é o maior conselheiro para o fracasso do diplomata.

Charles Chambrun perguntou certa vez a Jules Cambon: "Por que - Senhor Embaixador não escreve as suas memórias?" E, incontinente, respondeu o autor de Le Diplomate: "Escreva-as, meu amigo, escreva-as, já que as conhece, pois bem sabe que elas não mais me pertencem. Não posso fazer o elogio de mim mesmo e, apesar de ser candidato à Academia, nada publiquei. Essa circunstância, aliás, oferece a vantagem de que ninguém poderá dizer que escrevo mal..."

Em verdade, a autocrítica ainda é o melhor sentido de quem aspira realmente a atingir a meta do sucesso. NoAILles, Embaixador da França em Berlim, respondera, um dia, a quem the observara por que permanecia junto à janela aberta numa fria e nebulosa manhã de outubro: Je cherche mon petit rayon de soleil. O diplomata procura no clima da diplomacia, que é de imprevistas variações, o "seu pequeno raio de sol" - o segrêdo da carreira.

O diplomata deve ouvir muito, falar pouco e escrever bem. A eloquiência é inimiga da diplomacia. A eloqüência é a arte de atiçar paixões e a diplomacia é a arte de apaziguar os ânimos. Não basta, em diplomacia, conhecer a medida de cada palavra. A dissecação é trabalho de analista; emoldurar é obra de artista. Um é o técnico, outro é o esteta. E o diplomata é, ao mesmo tempo, o artífice e o artista. Chateaubriand é um dos belos exemplos: o Embaixador jamais esqueceu o homem de letras. Parte das Mèmoires d'Outre Tombe foi escrita quando de sua missão em Londres. O Quai d'Orsay, no ciclo brilhante de Philippe Berthelot, era o paraíso dos poetas.

O diplomata participa da vida tumultuosa do mundo e vive sòmente para o mundo silencioso da Chancelaria. Pensa e escreve o que os lábios não balbuciam. Eem avisado anda o diplomata que se ajusta ao espírito das instruções e máximas que o Cardeal Richelieu ditou para si mesmo. Os diplomatas de antanho e os de agora falam a mesma linguagem perspicaz: n'avoir point l'esprit distrait ni l'air triste ou mélancolique quand quelqu'un parle et y apporter une vive attention, ainsi que beautcoup de ǵrâce, mais plus par l'attention et le silence que par la parole et l'applaudissement.

Ainda se perfuma o século XX com os incensos da Renascença. Imenso é o horizonte da diplomácia. As múltiplas tonalidades da carreira situam o diplomata em diversos ângulos da cultura. A sagacidade de saber aplicar as normas é que define o diplomata. Digno de uma antologia diplomática é a telegrama que PALÉologue, Embaixador em São Petersburgo, dirigiu ao Quai d'Orsay em setembro de 1915. E que dizer dos documentos históricos de Sir Eric Philipps ou de André François Poncet? O impecável estilo diplomático dêsses documentos leva-nos a pensar na famosa circular de LAMARTINE, então Ministro dos Negócios Estrangeiros, invocando a necessidade da harmonia das Nações em benefício dos povos livres: "Govêrno de todos, a República cultua a paz. A guerra é quase sempre o fruto de uma 
ditadura. A República aspira a uma glória decorrente de seu próprio trabalho e não por meio dos Césares." O poeta de ontem, que foi Lamartine, versejaria ainda hoje:

Et quand je dis en moi-même:

Où sont ceux que ton coeur aime?

E o Conde de Gobineau? Anatole France assim o retratou: "Ena um grande diabo perfeitamente simples e, muito espirituoso; sabia-se que êle escrevia livros, mas ninguém os havia lido; a verdade é que êle era tocado pelo gênio". Era bem um "grande diabo" e nós não o ignoramos...

Mais do que os dourados fios de prata, que bordam o tradicional uniforme - símbolo de um élite espiritual - ressaltam, antes de tudo, no diplomata, as grandes virtudes cinzeladas pelas imagens discretas da inteligência. Perdôa-se uma afronta, mas não o ridículo. O diário do Conde Rodolphe Apponyi é um exemplo. Já o Papa Bonifácio VII chamava irônicamente os diplomatas florentinos de "Quinto elemento". A definição era justa e oportuna: é que na brilhante lista dos Embaixadores de Florença havia Dante, Petrarca, Bocacio...

Curioso: numa época de propalado materialismo, é o século XX um ciclo renascente do apuro espiritual e do requinte da elegância. Há, em tudo, um desejo incontido de conhecer os homens e as coisas. Luta-se afanosamente por um bem que, por mercê de Deus, há-de existir um dia entre os povos: a fraternidade. Só há um meio - o mais seguro de todos - que nos conduz a êsse nobre objetivo da vida humana: a cultura. E o diplomata é o agente dessa cultura pacificadora.

Já esclamava um velho Embaixador: C'est quand les ambassadeurs connaissent les poids des mots que les peuples ont chance del connaître la paix...

\section{DIPLOMACIA DEMOCRÁTICA}

... Como tôdas as profissões, a carreira diplomática possui regras próprias, ou melhor, o seu ritual. Para penetrá-lo, faz-se mister um certo período de adaptação e aprendizagem. Não se trata, porém, de uma arte misteriosa, cheia de ritos complicados, ou de regras guardadas em segrêdo por uns quantos iniciados. Nada disso. A diplomacia moderna, como já vimos, é essencialmente econômica e democrática. Ela tira sua fôrça do direito internacional, que the fornece a doutrina e the indica o caminho a seguir. O direitodiplomático, por sua vez, cujo campo de ação é constituído pela técnica das relações entre os Estados, coordena êsses elementos e os aplica na prática. Pode dizer-se, assim, que um é o veículo do outro, ou melhor, o seu instrumento imprescindível. E como a execução, em geral, vale tanto quanto a concepção, fôrça é concluir que o direito diplomático constitui elemento indispensável à fiel observância das regras estabelecidas pelo direito internacional. Ambos contribuem, destarte, em partes iguais, para o êxito da diplomacia. Embaixador Rubens Ferreira de Melo. 